\title{
The Spectre of the Present: Time, Presentism and the Writing of Contemporary History
}

\author{
Jenny Andersson, The Future of the World: Futurology, Futurists, and the Struggle for the Post Cold \\ War Imagination (Oxford: Oxford University Press, 2018) \\ Aleida Assmann, Is Time out of Joint? On the Rise and Fall of the Modern Time Regime (Ithaca: \\ Cornell University Press, 2020)
}

Dan Edelstein, Stefanos Geroulanos, and Natasha Wheatley (eds), Power and Time: Temporalities in Conflict and the Making of History (Chicago: Chicago University Press, 2020)

Fernando Esposito (ed.), Zeitenwandel: Transformationen geschichtlicher Zeitlichkeit nach dem Boom (Göttingen: Vandenhoeck \& Ruprecht, 2017)

Zoltán Boldizsár Simon, History in Times of Unprecedented Change: A Theory for the 21 st Century (London: Bloomsbury, 2019)

Marek Tamm and Laurent Olivier (eds), Rethinking Historical Time: New Approaches to Presentism (London: Bloomsbury, 2019)

Presentism used to be so simple. In the old vernacular, it referred to a tendency to view the past from the perspective of the present (or, at its most extreme, maybe even use the past to illuminate the present). Historians disagreed furiously on the intellectual virtues of orienting their views of the past to the needs of the current day. But the content of the term itself was rarely disputed.1

The last two decades have seen a profusion of works that have complicated our understanding of how historians connect past and present. In his recent 'Defense of Presentism', David Armitage identifies at least five different meanings of the term, gathered from recent historical works.2 But, within a European context at least, the most influential - and controversial - intervention in our conception of a historical present is that of the French classicist François Hartog. In his Regimes of Historicity (2003), Hartog charts the late twentieth-century rise in Western Europe of what he terms a 'regime of presentism', in which our inability either to secure a meaningful purchase on the past or to place our collective hopes in an envisioned future mires us in the quicksand of an infinitely expansive and interminable present. As the limitless acceleration of modern life surpasses human capacities of comprehension, our temporal bearings are dissolved entirely. Unmoored from history, we look to the past and see only ourselves. Past and future become nothing more than extensions of now.

In Hartog's hands, then, 'presentism' is no longer a methodological or even epistemological matter, but the diagnosis of an entire cultural condition. Within a 'regime of presentism', the present

\footnotetext{
1 In a 2002 essay entitled 'Against Presentism', Lynn Hunt listed two forms of presentism: firstly, 'the tendency to interpret the past in presentist terms', and secondly 'the shift of general historical interest toward the contemporary period and away from the more distant past'; Lynn Hunt, 'Against Presentism', May 1, 2002, https://www.historians.org/publications-and-directories/perspectives-on-history/may-2002/against-presentism (last visited 14 April 2020).

2 David Armitage, 'In Defense of Presentism' in Darrin M. McMahon (ed.), History and Human Flourishing, (forthcoming, 2020), https://scholar.harvard.edu/files/armitage/files/in_defence_of_presentism.pdf (last visited 20 April 2020).
} 
constitutes the full horizon within which historical thinking is possible. 3 We are no longer oriented to the future and enchanted by the inevitability of progress, as were the nineteenth-century modernists who shaped history as a professional discipline.4 Nor do we view temporal distance as a sufficient condition for objectivity. The present is no longer made past, but the past is made present. In one sense, the problem posed by this particular species of 'presentism' is a simple one: the discipline of history, and the distinctive methods, approaches and assumptions that mark it out, is a product of a now-outdated time sensibility (or 'chronotope', to adopt the term of Hans Ulrich Gumbrecht).5 And if the very basis of the discipline itself demands an ontological disjunction between past and present, then the challenge of 'presentism' might even be a fundamental one.

Small wonder, then, that one leading theorist of history feels moved to write that the 'spectre of presentism is haunting Europe' ${ }^{6}$ Chris Lorenz argues that the past forty years or so have witnessed the total dissolution of both the temporal and spatial coordinates within which history had traditionally been conceived. The breakdown of Hartog's 'modern regime of historicity' closely corresponded with the demise of a modern 'regime of territoriality' (Charles Maier), which elevated the nation-state as the privileged actor of historical progress.7 But this framework no longer holds. Instead, Lorenz envisages a notion of contemporary history that is liberated from mere chronology and more closely attuned to what Walter Benjamin termed 'actualization' - the activation of latent pasts in a given present. Hartog's 'regime of presentism', he argues, might therefore be seen as having two - arguably contradictory - meanings: as a description of our contemporary historical epoch, and as this epoch's distinctive epistemological framework for understanding the past.8 Whichever way we look at it, contemporary history must map itself onto a very different temporal axis to that which preceded it.

Debates about presentism reflect a wider scholarly effort to grapple with the nature of historical time. A spate of new books on the structure, experience and even ontology of historical time suggests that the discipline really is engaged in a thorough deconstruction of its own temporal fundaments. But, as this essay seeks to demonstrate, the dizzying diversity of their content reveals just how far we are from a unified view of the matter. For the study of contemporary history, the flourishing field of time studies portends possibilities and challenges in equal measure.

Hartog's influence looms large in a new volume edited by Marek Tamm and Laurent Olivier, Rethinking Historical Time: New Approaches to Presentism. Here, the editors' aim is to explore the creative potential in opening up our understanding of historical time to accommodate a greater variety of temporal configurations, untethered from the old 'historicist' belief in a past rendered evermore distant by the passage of time. In substantiating this claim, Tamm and Olivier conscript Frederick

\footnotetext{
3 A recent Past and Present 'Viewpoint' series on presentism stuck more closely to the traditional meaning; see Alexandra Walsham, 'Introduction: Past and...Presentism', Past and Present 234 (2017), pp. 213-17.

4 In this sense, there is some evident overlap between Hartog's 'regime of presentism' and postmodernism. even if, as Stephen Smith points out, 'his book contains not a single mention of this concept'; S. A. Smith, 'China, Revolution and Presentism', Past and Present 234 (2017), pp. 276-77.

5 Hans Ulrich Gumbrecht, Our Broad Present: Time and Contemporary Culture (New York: Columbia University Press, 2014).

6 Chris Lorenz, 'Out of Time? Some Critical Reflections on François Hartog's Presentism' in Marek Tamm and Laurent Olivier (eds), Rethinking Historical Time: New Approaches to Presentism (London: Bloomsbury, 2019), p. 22.

7 Chris Lorenz, 'Unstuck in Time: Or, the Sudden Presence of the Past' in Karin Tilmans, Frank van Vree, and Jay Winter (eds), Performing the Past: Memory, History, and Identity in Modern Europe (Amsterdam: Amsterdam University Press, 2010), p. 80.

8 Lorenz, 'Out of Time?'; Charles S. Maier, 'Transformations of Territoriality 1600-2000' in Gunilla Budde, Sebastian Conrad and Oliver Jansz (eds), Transnationale Geschichte. Themen, Tendenzen und Theorien (Göttingen: Vandenhoeck \& Ruprecht, 2006), pp. 32-56.
} 
Beiser's argument that 'historicism' never really died; that its core tenets simply became so profoundly embedded in the habitus of professional history-writers that it became near-impossible to conceive of history otherwise.9 But historicism's unquestioned assumptions about the structure of historical time both underlay and legitimised Eurocentric models of progress, universality and temporal synchronisation that have for some time been coming under critical pressure. From this it follows that charting new paths in historical writing may require a rethinking of our relationship with historical time.

So, where does presentism fit into this picture? To follow the lines of enquiry presented in this volume, 'presentism' confronts us with two major intellectual challenges when seeking to fashion a mode of historical understanding appropriate for a post-historicist age. The first concerns how we perceive 'the preservation of the past in the present'.10 Critiquing the historicist principle that our distance from past events is measured solely by chronology, the presentist viewpoint compels us to acknowledge the fiction that we can ever outrun the past and simply let it recede toward our temporal horizon. Witness the ominous vocabulary deployed in the recent deconstructionist literature: the past is 'latent', it has 'presence', it 'haunts' us.11 Past and present do not occupy distinctive ontological territories but collectively constitute one dynamic field of tension.

The second concerns the problem of 'contemporaneity'. Contemporaneity has surfaced as a bogeyman in many of the recent historical efforts to recover the past temporalities that lie beneath the singular, monolithic, and capitalised History which Reinhart Koselleck famously identified as the flagship temporality of western modernity.12 This concept produced and legitimised civilizational hierarchies, positioning Europeans at the vanguard of progress and condemning all others, in Dipesh Chakrabarty's memorable phrase, to the 'imaginary waiting room of history'.13 To this end, Tamm and Olivier approvingly cite Berber Bevernage's call for historians to 'break with the idea of the fully contemporaneous present and instead embrace that of radical noncontemporaneity or noncoevalness' a challenge to historicist time echoed powerfully in Chakrabarty's postcolonial critique. 14

Setting out from these premises, Rethinking Historical Time is packed with efforts to perforate historicist time. The authors featured in the volume invoke twentieth-century European thinkers who perceived the empty, abstract and irreversible time of historicism as alienating, destructive or intellectually suspect, and who aimed to liberate western thought from its heavy shackles. Today's theorists can hark back to an impressive pantheon of intellectual forebears. Tamm, Olivier and Johannes Grave detail the creative power of two in particular: the art historian Aby Warburg, with his non-linear vision of the moment as a dense palimpsest of past, present and future; and Walter Benjamin, who radically rejected mechanical causality in favour of a historical topography in which the past would momentarily 'actualize' in the present. Other non-historicist temporalities explored in this book include the ahistorical, eternal Jewish time of Franz Rosenzweig; Mircea Eliade's rejection

\footnotetext{
9 Frederick Beiser, The German Historicist Tradition (Oxford: Oxford University Press, 2011). 10 Marek Tamm and Laurent Olivier, 'Introduction: Rethinking Historical Time' in Tamm and Olivier, Rethinking Historical Time, p. 2.

11 As adumbrated by Hans Ulrich Gumbrecht, Eelco Runia and Ethan Kleinberg respectively; see the discussion in Zoltán Boldizsár Simon, History in Times of Unprecedented Change: A Theory for the 21st Century (London: Bloomsbury, 2019), pp. 69-74. 12 Reinhart Koselleck, 'Geschichte/Historie' in Otto Brunner, Werner Conze, and Reinhart Koselleck (eds.), Geschichtliche Grundbegriffe: Historisches Lexikon zur politisch-sozialen Sprache in Deutschland, vol. 2, (Stuttgart: Klett, 1975) pp. 647-717.

13 Dipesh Chakrabarty, Provincializing Europe: Postcolonial Thought and Historical Difference (2nd ed., Princeton and Oxford: Princeton University Press, 2008), p. 8.

14 Quoted in Tamm and Olivier, 'Introduction', p. 2.
} 
of historicism and turn to the transcendent power of 'mythical time' (see Liisi Keedus' essay on time and interwar intellectual 'outcasts'); Martin Heidegger's embrace of the temporality of the 'moment' (Augenblick) as a 'temporality of revolutionary action' (Hans Ruin); and, of course, the plural time strata envisaged, in their different ways, by Fernand Braudel and Reinhart Koselleck.

In addition to theoretical contributions and intellectual histories, one finds in this volume some insightful applications to historical practice of a pluritemporal approach. Victoria Fareld, for example, argues that historians have often felt threatened by 'presentism' precisely because the sense of 'difference between past and present' that presentism collapses is the very foundation on which they perceive historical understanding to be possible.15 Analysing the debates surrounding the 'Rhodes Must Fall' campaign, Fareld points out that even sympathetic historians have seen the effort to remove burdened statues as an inauthentic 'falsification of history': in other words, as presentism in its most damaging sense. 16 This perception contrasts with that of the activists, whose claims are predicated on the conviction that certain pasts necessarily remain active in the present. Fareld therefore reads the 'Rhodes Must Fall' debate as essentially a story of two competing historicities, with the activists explicitly challenging the habits of those schooled in historicist thinking by drawing attention to the idea that their assumed 'boundaries between past and present are not', in fact, 'neutral or objective categories'. 17 Conceiving the debate in these terms, she convincingly concludes, 'can help us move beyond the question of presentism as the opposite to historical understanding'.18

Approaching the question of heritage temporalities from a very different perspective, meanwhile, Torgeir Rinke Bangstad excavates the layered temporal textures of individual material objects. Employing the case study of a post-war house from Finnmark in far northern Norway which was dismantled and reconstructed at Oslo's Norsk Folkemuseum in 2019, Bangstad demonstrates how the reduction of built heritage to the singular perspective of any one regime of historicity disregards the wealth of temporalities that inhere in the object itself.19 In other words, the 'temporal identities' of a material object like the Finnmark house do not derive only from its point of historical origin or from its present-day function. 20 Rather, it contains its own temporal processes, anchored in its very materiality: 'even within one predominant mode of relating to and making sense of time, the time of the thing is not one but many'.21 To posit a binary alternative between 'historicism' and 'presentism', in other words, is to illuminate only a small fragment of the temporal spectrum.

The approaches of Bangstad and Fareld illustrate the potential for thinking about the complex character of our contemporary chronotope in ways that are more dynamic than implied by the image of a single presentist 'regime'. And they are not alone in rejecting Hartog's notion of presentism as being both too pessimistic and too reductive. Indeed, a number of critics have detected a sense of lament in Hartog's work: decades of historians' polemics demarcating their craft from the ambush of 'memory' and 'heritage' - not to mention 'postmodernism' - seem to have left him weary.22 There seems little doubt that he perceives the limitations of our 'presentist' horizons very acutely indeed. But a more penetrating critique attacks Hartog's 'regime of presentism' for being just as reductive as the

15 Victoria Fareld, 'Coming to Terms with the Past: Exploring the Chrononormativity of Historical Time' in Tamm and Olivier, Rethinking Historical Time, p. 66.

16 Ibid., p. 62.

17 Ibid., p. 64.

18 Ibid., p. 66.

19 Torgeir Rinke Bangstad, 'Heritage and the Untimely' in Tamm and Olivier, Rethinking Historical Time, p. 150.

20 Ibid., p. 160.

21 Ibid.

22 Lorenz, 'Out of Time?' p. 36. 
modernist regime of historicity it supposedly supersedes.23 As the essays in this book help demonstrate, historians might find 'presentism' to be a more productive foundation of research if they see it as a gateway to a more pluritemporal approach rather than simply another homogenous configuration of 'historicity'.

In sum, Rethinking Historical Time sets out to emancipate 'presentism' from the condescension of the historicists and to explore critically the concept's interdisciplinary possibilities. And on this score at least, the book contains many promising lines of enquiry. At the same time, the diffuseness of the concept muffles the resonance of the debate. Many more words of this volume seem to be dedicated to explicating, critiquing and expanding the notion of 'presentism' than exploring its hermeneutic potential. It is no doubt easier to tout the virtues of attuning humanities research to 'multiple temporalities' - particularly when set in contrast to self-limiting, Eurocentric narratives - than it is to demonstrate how this research might be executed as everyday historical practice. These essays take the reader into the anomie of Hartog's presentism, but they do not really succeed in bringing her out again. Both the shipwrecked 'historicist' vision of empty, steady-state time and Hartog's invocation of historical time rendered immobile in a presentist morass still dominate the scenery, for lack of any fully elaborated alternative.

What to do when the old 'historicist' temporal assumptions no longer hold but 'presentism' falls short as a characterisation of our contemporary sense of historical time? One option is to acknowledge the profundity of the transformations contained within our contemporary chronotope without accepting the sufficiency of 'presentism' as a diagnosis. This, in general terms, is the approach taken by Zoltán Boldizsár Simon in his ambitious work of historical theory, History in Times of Unprecedented Change. Simon sets out from the premise that the disruptive changes of the post-war era - including 'nuclear warfare, anthropogenic climate change and technological visions of artificial intelligence, bioengineering, transhumanism and radical enhancement' 24 - are of such a magnitude that we must question whether they can meaningfully be integrated into a historical continuum. In other words, we must seriously question the capacity of traditional historical thinking to fully grasp the global developments that characterise the world of today. Simon's aim is to produce a conceptual apparatus and vocabulary that can capture this contemporary 'historical sensibility'.

There is a simple elegance to Simon's theory. A peculiarly modern 'historical sensibility', he tells us, emerged sometime in the late eighteenth century to help us cope with the changes that modernity habitually unfolds. It served to inoculate us against the terror of novelty by embedding it in one rational, continuous process. In this way, even the most dramatic experiences of rupture could be 'tamed' and rationalised. Hence, the very idea of unprecedented change is, by definition, an existential challenge to our traditional historical sensibility. And yet, this is exactly the type of change that Western societies now need to confront, as 'experience' and 'expectation' (to use the Koselleckian categories that are rarely far away from any of our featured authors' lips) come to 'diverge completely'.25 What he offers in place of the old historical thinking is a theory in which the past and the future are defined by distinctive - not continuous - ontological subjects. Instead of the consistent, 'self-identical subject' that furnished traditional history with its sense of unity and stability, Simon postulates a vision of historical time defined by an unremitting 'displacement and replacement of the subject' .26 In other words, he advocates a radical shift from historical thinking in which the future is

23 Tamm and Olivier, 'Introduction', pp. 35-36.

24 Zoltán Boldizsár Simon, History in Times of Unprecedented Change: A Theory for the 21 st Century (London:

Bloomsbury, 2019), p. 67

25 Ibid. p. 62.

26 Ibid. 
'always already...contained in the past' to one which can accommodate genuine discontinuity.27 In his view, the sting of the Hegelian bite is not the lure of progress, or even the more neutral categories of 'development' or 'process'; it is the very idea that historical time is continuous at all.

Fundamentally, History in Times of Unprecedented Change argues that the unique qualities of the post-war Western world have imparted radically new expectations of the future and by extension have upended the future orientation of our old historical sensibility. In opposition to Hartog, however, Simon argues that the existential terror posed by new challenges like nuclear war, climate change and artificial intelligence does not constrain us to seeing only an extension of the present whenever we look to the future. Instead, the unprecedented character of these challenges demands a fundamental reconception of how we envisage change in - and to - the human world. 'History', Simon defiantly declaims, 'moves again': the future has 'returned'.28 But this is neither the 'history' nor the 'future' we thought we knew.

Depending on how one reads it, then, we are either post-presentist, or we were never presentist to begin with. But whichever might be the case, Simon is surely right to redirect our attention away from the socio-political concerns that drive the temporal reflections of Hartog, Gumbrecht and Aleida Assmann (see below), and toward the spheres of science and technology, which continue to evince a relentlessly modern obsession with novelty, reinvention and rupture. This shift in focus helps break down the idea that there can ever exist a full transition between two all-embracing regimes of historicity - and indeed, leads one to wonder whether the contrast between the two spheres might even prove a productive tension in exploring the temporalities of contemporary political and social conflicts.

It is difficult not to be impressed by the scale of Simon's ambition. His theory neatly captures some of the intellectual blind spots generated by history's engrained predisposition to continuity over rupture. Nevertheless, it is not entirely clear why these contemporary global, human challenges ought to arrogate to themselves an exclusive right to 'unprecedentedness', denied even to the most destructive novelties of the early twentieth century. Simon returns to this question in his final chapter, in which he reflects on whether the theory of discontinuous history he advocates can even be classified as 'history' at all. This is an important question: can we meaningfully reconfigure the temporal assumptions that undergird the discipline without fundamentally restructuring the edifice itself? Are we engaging in something other than 'history' when we do so? Simon for one is unsure: 'You decide!' he concludes, rather unsatisfyingly.

This uncertainty is instructive when we further consider some of the consequences of the so-called temporal turn for historical practice. In this respect, we might imagine two potential outcomes of the theories advanced by the scholars we have met so far. One, to follow Christopher Clark, is to see the 'temporal turn' as simply 'one of those re-patternings of attention by which the discipline of history periodically refreshes itself', on a par with the cultural and linguistic turns of generations past.29 By this view, history will simply absorb the 'temporal turn' in its stride. Time will become just another aspect of historical experience of which the historian must be cognizant, and 'time history' will settle as a recognised subfield of research that is effortlessly synthesised into the discipline at large. The deconstruction of historical time, in other words, poses no particular threat to history's

27 Ibid., p. 59. See also Eelco Runia, Moved by the Past: Discontinuity and Historical Mutation (New York: Columbia University Press, 2014).

28 Simon, History in Times of Unprecedented Change, pp. 46, 50

29 Christopher Clark, Time and Power: Visions of History in German Politics, from the Thirty Years' War to the

Third Reich (Princeton: Princeton University Press, 2019), p. 6. 
epistemological traditions, despite the apparent fundamentality of certain temporal assumptions to the historian's trade.

The other possibility portended by Simon's conclusion is altogether gloomier: namely, that anything still recognisable as 'history' simply loses its orientation when wrenched out of the modern time regime that produced it. Does the deconstruction of previous assumptions about time represent a unique threat to historical practice? Is 'time' a cuckoo egg in the historian's nest? This is not a fear that, to my knowledge at least, has been articulated by any leading historian: so far, the 'temporal turn' has not stimulated the kind of existential hysteria that accompanied, say, the rise of postmodernism in the 1980s and 90s.30 Pleasingly, historians have seemed quite open to critical reflection on the temporal fundaments of their own discipline, and to allow their study of historical time to feed reflexively into their practice. Of course, this might merely reflect the fact that we are still only at the beginning of theorising how the deconstruction of our previous assumptions about historical time might alter the actual work of historical writing. On this front, it seems, we must wait and see where future research leads us.

In the current literature, meanwhile, one can detect two possible responses to this situation. The first is to fully embrace the collapse of the old assumptions of historical knowledge and to fashion upon their smouldering ruins some novel ideas of what history can be. In this respect, the works of Simon, Lorenz and Achim Landwehr serve as examples.31 But how their theories might be applied to historical practice presents a real challenge to the imagination. A more productive response might therefore be to re-evaluate and even replenish some of the old assumptions in light of our new findings, and to subject our shifts in temporal sensibilities to historical scrutiny - in other words, to historicise historicization. In broad terms, this is the approach of the works to which I now turn.

Acknowledging the tectonic shifts that have occurred in Western temporal sensibilities over the past generation or two, Aleida Assmann sees no need for panic. For her, the problem is not 'presentism', its symptoms or its causes - the problem was rather the self-universalising arrogance of a modern time regime which now, mercifully, is being undone.32 The breakdown of the 'modern time regime' with its 'strict separation of temporal registers',33 and the more fractured, recursive and plural temporalities that are emerging in its wake, allow 'for the cultural foundations of the historical vocation to be more strongly implicated and reflected in the work of history itself' .34 In other words, by historicizing the

30 Though one might indeed view the 'temporal turn' as a further stage in the postmodernist project. As Ernst Breisach observed in 2003, '[c]onsidering the importance of the postmodernist revision of the temporal dimension of human life - be it the change and continuity dichotomy or the progressive linear concept of time the discussion of that topic has been surprisingly sketchy'. Despite the fact that some postmodernists explicitly rejected historical time as 'an invention of modern Western civilization . . no direct discussion of the role of time in postmodernism generally and the metanarrative specifically ensued' Ernst Breisach, On the Future of History: The Postmodernist Challenge and its Aftermath (Chicago and London: University of Chicago Press, 2003), pp. 139-140.

31 Achim Landwehr, Die anwesende Abwesenheit der Vergangenheit. Essay zur Geschichtstheorie (Frankfurt a. M.: Fischer, 2016).

32 Indeed, in Assmann's historicizing take on the waning of the 'modern time regime' one can detect an echo of Geoffrey Barraclough's classic 1966 defence of the practice of contemporary history. Attacking those who condemned contemporary history as a 'newfangled notion' developed in response to the profound political questions posed by the early twentieth-century, Barraclough retorted: 'it is not unfair to answer that what was newfangled was not a concept firmly anchored to the present but, on the contrary, the nineteenth-century notion of history as something dedicated entirely to the past'; Geoffrey Barraclough, An Introduction to Contemporary History (London: Penguin, 1967), p. 7.

33 Aleida Assmann, Is Time out of Joint? On the Rise and Fall of the Modern Time Regime (Ithaca: Cornell University Press, 2020), p. 199.

34 Ibid., p. 197. 
'modern time regime' and its eventual demise, we might actually enrich our possibilities for historical thinking.

For many years now, Assmann has been one of the most original and perceptive thinkers on the relationship between time, memory and history. It is therefore very welcome that Cornell University Press has issued an English translation of her 2013 book Ist die Zeit aus den Fugen? ('Is Time out of Joint?'), in which Assmann explicates the rise and fall of the 'modern time regime' that governed historical thinking from the late eighteenth- to the late twentieth-century. Superbly translated by Sarah Clift, Is Time out of Joint? produces an evocative picture of the temptations and vices of modern historical time, assembled from an intriguingly wide and eclectic range of cultural sources.

Like Hartog, Assmann sees the 'modern time regime' as fundamentally future-oriented. And like Hartog, she identifies its crisis as setting in by the 1980s.35 Unlike Hartog (and Simon), however, she does not see the post-modern time regime as defined by a complete disjuncture between the Erfahrungsraum ('realm of experience') and the Erwartungshorizont ('horizon of expectation'). On the contrary, she maintains that ' $[\mathrm{w}]$ herever we look, the gulf separating the realm of experience and the horizon of expectation is being bridged, and the past and present are again becoming more tightly bound to one another'.36 Reacting against modernity's uncompromising insistence that we 'forget the past' and fix our gaze squarely on the future, our contemporary chronotope permits the past to assume new meaning in the shape of collective memory and social identity. And in this way, the death of the 'modern time regime' - far from inaugurating an era of 'presentism' - actually signals a return to 'normalcy'.37 In a fundamental sense, then, its collapse permits a realignment of our temporal configurations into something more organic and mobile - even, perhaps, 'premodern'.38 This, to be clear, is something to be celebrated, not lamented.

As a consequence of adopting this standpoint, Assmann's story - again, unlike Hartog's - is not diminished by any sense of loss for the old certainties furnished by the vanished time regime she describes. Assmann warns against 'dismissing the new time regime wholesale and throwing ourselves into a battle of words between historians and memorialists'. 39 Instead, we are better served by recognising that there are great reserves of creative potential waiting to be tapped in a post-modern chronotope that collapses all essentialising distinctions between 'history' and 'memory'. And in this respect, the assumptions of the 'modern time regime' still have a role to play: as Assmann sees it, this regime 'has not completely lost its authority; rather, as more and more avenues for accessing the past have opened up, it has been placed within certain limits'.40 But as a starting point, we must acknowledge that '[a]ll time regimes provide a groundwork for unspoken values, interpretations of history, and meaningful activity', 41 including the time regime that birthed our modern idea of history.

It follows that Assmann is more reluctant than Tamm and Olivier to define as 'historicist' all modes of historical thinking that played out within the contours of her modern time regime. Indeed, in many respects her insistence on 'historicization' faithfully reproduces some of the axioms of the old

\footnotetext{
35 Ibid., p. 195.

36 Ibid., p. 199.

37 Ibid. University Press, 1993), p. 133.

39 Assmann, Is Time out of Joint?, p. 199.

40 Ibid., p. 169.

${ }_{41}$ Ibid., p. 8.
}

38 Lorenz, 'Out of Time?' p. 35. In describing the modern 'invention of the historical', Assmann cites Bruno Latour's claim that 'moderns' are 'cut off from a past that is maintained in a state of artificial survival due only to historicism'; Bruno Latour, We Have Never Been Modern (trans. Catherine Porter, Cambridge MA: Harvard 
'historicist' thinking, including its dependence on temporal distance: 'it is only when alternatives present themselves on the horizon that the shape of something first becomes visible', she writes; 'until then, it had appeared as the self-evident and natural environment of the way things are'.42 The recombination of temporal impetuses that define our contemporary chronotope, then, should not exclude the possibility that different time regimes might fertilise one another.

While Assmann aims to chart the demise of an entire time regime, other historians have begun analysing how this collapse manifested itself in specific historical experiences. This is the undergirding purpose of Fernando Esposito's edited volume Zeitenwandel: Transformationen geschichtlicher Zeitlichkeit nach dem Boom. The book emerges from the Nach dem Boom contemporary history project undertaken at the University of Trier and the Eberhard Karls University in Tübingen, which aims to explore the deep structural shifts that have taken place in European society since the early 1970s. The principal aim of Zeitenwandel is to explore how changes in temporal experiences, and understandings of the relationship between past, present and future, were constituent aspects of these shifts. As Esposito puts it in his introduction, '[d]id there take place in these decades a structural intellectual break, even a paradigm shift, in the matter of time?' 43 The fact that the era generated a wide circulation of temporally-themed discourses - 'postmodernity, the end of grand narratives, experiences of acceleration, pursuits of nostalgia, conservative inertia (Beharrungen), Posthistoire', as Achim Landwehr lists them - certainly suggests a profound loss of faith in the old certitudes of historicist time.44 Indeed, Esposito goes so far as to suggest that the era witnessed a 'second crisis of historicism' triggered by waves of decolonisation, the failures of modernization, and a belated recognition of the destructive pathologies of modernity. 45

The essays presented in Zeitenwandel investigate how shifts in time horizons were reflected in West German subcultures, protest cultures, political cultures and media discourses in the 1970s and 80s. Lukas J. Hezel, for instance, interrogates the temporal languages of radical youth movements, situating them within the more general crisis of the future that characterised the cultural atmosphere of the 'Nach dem Boom' era.46 Starting from the important observation that 'expectations of the future exercise a great influence over political processes and dynamics', he traces the influence of a loss of future prospects over the new youth movements, with their recourse to radical, nihilistic slogans like 'no future' and a 'militant presentism' that manifested itself in a politics of immediacy and spontaneous action.47 Sticking with the theme of alternative cultures, Silke Mende traces the temporal languages attendant upon the emergence of new protest movements in the early 1980s. Mende argues that the immense popularity of Michael Ende's 1973 novel Momo, in which a child protagonist seeks to recapture lost time from a parasitic band of 'time-thieves', was indicative of the shifting timesentiments that fed into a budding ecological consciousness within West German society. One manifestation of these shifts was the emergence of the Green Party, which was able to make a compelling political appeal to 'end of progress' sentiments by invoking Edmund Burke's idea of an

42 Ibid., p. 175.

43 Fernando Esposito, 'Zeitenwandel. Transformationen geschichtlicher Zeitlichkeit nach dem Boom - eine Einführung' in Fernando Esposito (ed.), Zeitenwandel: Transformationen geschichtlicher Zeitlichkeit nach dem Boom (Göttingen: Vandenhoeck \& Ruprecht, 2017), p. 7

44 Achim Landwehr, 'Die vielen, die anwesenden und die abwesenden Zeiten. Zum Problem der ZeitGeschichte und der Geschichtszeiten’ in Esposito, Zeitenwandel, pp. 230-31.

45 Esposito, 'Zeitenwandel', p. 54.

46 Lukas J. Hezel “"Was gibt es zu verlieren, wo es kein Morgen gibt?” Chronopolitik und Radikalisierung in der Jugdendrevolte 1980/81 and bei den Autonomen' in Esposito, Zeitenwandel, p. 122.

47 Ibid., pp. 122, 149. 
intergenerational contract.48 Finally, Elke Seefried explores shifts in the rhetoric and policy platforms of the Social Democratic Party throughout the 1970s and 1980s. Initially, Seefried demonstrates, the party's future visions were wedded to the modern time regime that reigned during the party's origins in the late nineteenth-century. But as concepts like 'progress' and 'modernisation' lost their lustre and, indeed, their relevance, the SPD was forced to recalibrate its relationship to the future and the language through which this relationship was articulated.49 As the party's 'long-term plans for organising the future eroded', she concludes, it increasingly 'developed a "presentist" understanding of time'.50

As these studies indicate, many of the essential time transformations of the crisis era found expression as new perspectives on the future. But, as Tobias Becker shows, equally suggestive of the general shift was a surge of media interest in the phenomenon of nostalgia. Becker's work on the so-called nostalgia wave in the Federal Republic during the 1970s detects how contemporaries identified and explained a perceived intensification of popular interest in the past. Nostalgia, he compellingly suggests, was less a self-contained phenomenon than a discourse, facilitated and intensified by the era's unprecedented consciousness of matters relating to time and temporality. As such, 'nostalgia' often became a disparaging term deployed by the self-professed guardians of 'genuine' historical knowledge to denigrate the superficial 'past' being promoted by the media, popular culture and the tourism industry.

To some extent, the authors featured here are all agreed that the 1970s and 1980s constitute an especially fruitful period to study time transformations in Western Europe. But it is not necessarily the passing of the 'modern time regime' that interests them, still less the notion that something called 'presentism' filled in the resulting gap. Rather, their studies reveal the effects of the crisis era on generating novel temporal configurations in West Germany's political and cultural domains. Hence, what is of particular value in this volume is its means of demonstrating how a close analysis of shifting time horizons within narrow chronological and spatial limits can help disclose the temporal properties of more encompassing social shifts. Indeed, the high quality of these essays gives some cause to believe that these kinds of narrower case studies might prove more enlightening than the macro-level types of analyses that the language of 'time regimes' naturally seems to evoke.

Some of the advantages and disadvantages of a big-picture approach are on display in Jenny Andersson's study The Future of the World: Futurology, Futurists and the Struggle for the Post Cold War Imagination. Andersson focusses chiefly on the era immediately preceding that of Esposito's volume: a period in which the ideologies of progress, technocracy and human mastery of time attained unsurpassed levels of self-confidence. However, The Future of the World is not simply a study of how one regime of time folded into another. Rather, Andersson's ambition is to unearth the fields of tension that subsisted beneath this sense of epochal unity, even among those who most faithfully trusted in humankind's capacity to divine and master the future. As she frames it: "what marks the idea of the future in the post-war period is not, as historians have suggested, a sudden shift from progress to decline after 1973, but rather, a struggle between conceptions of world temporalities as indeed singular or plural'.51

\footnotetext{
${ }_{48}$ Silke Mende, 'Das “Momo"-Syndrom'. Zeitvorstellungen im alternativen Milieu und in den "neuen" Protestbewegungen' in Esposito, Zeitenwandel, p. 180. 49 Elke Seefried, 'Partei der Zukunft? Der Wandel des sozialdemokratischen Fortschrittsverständnisses 19602000' in Esposito, Zeitenwandel, p. 195. 50 Ibid., p. 194. 51 Jenny Andersson, The Future of the World: Futurology, Futurists, and the Struggle for the Post Cold War Imagination (Oxford: Oxford University Press, 2018), p. 215.
} 
In developing this argument, Andersson shines her spotlight on intellectuals active between the 1950s and 1970s as they wrote and exchanged ideas across borders, founding institutions and journals, penetrating deeply into the policy hearts of Cold War governments, and ultimately spawning a thriving industry of corporate consultancy. This was a complex and international scene: familiar figures like Alvin Toffler, Daniel Bell and Bertrand de Jouvenal feature among a pantheon of lesser known visionaries. Theirs were sometimes global ambitions, enclosing the totality of humanity in their fields of vision, and energised by a foundational optimism in the capabilities of science - in particular social science - to rationally manage the swelling complexities of mass society. But the skills and methods of future researchers and, later, futurologists, were also enrolled in the service of more parochial corporate or political concerns. Hence, the Cold War assumes an uneasy space in this story: sometimes as the very framework within which Andersson's actors operate, sometimes as a near-irrelevance. Futures research, Andersson argues, should not be viewed as either a domain of the Cold War nor an instantiation of East-West 'convergence'. Even if she incorporates both liberal and socialist approaches to future planning, her story is too complex to be captured within the binary oppositions of the Cold War.

More important to Andersson's study is the diversity of approaches and ambitions that inspired future researchers and futurologists. Their methods assumed multiple forms: systems analysis, cybernetics, Operations Research, the 'scenario method' developed by Hermann Kahn at the RAND Corporation, and his colleague Olaf Helmer's 'Delphi Panels' of experts. While some aimed at predicting, others aimed at planning. Within the complex milieu of futures research, Andersson shows, contingencies were every bit as important as certainties.

There are some important lessons to be drawn from Andersson's analysis about the way in which the future has been perceived, even by those who ostensibly embraced the modern time regime most enthusiastically. 'The future', Andersson observes, 'is not a universal element of a given history'.52 It is constructed, a product of reigning norms and thus intricately bound up with the new configurations of global power that any generation produces.53 And yet in practice, The Future of the World often lacks a wider sense of perspective. On the one hand, there is much to be said for Andersson's choice to privilege concept over context. It enables her study to glide across time, space and ideological systems, disclosing a cosmopolitan world of intellectual networks (even if it sometimes makes The Future of the World a difficult book to follow). But on the other hand, Andersson's attention is tightly focused on intellectuals: although we catch glimpses of the political climates and cultures in which her protagonists operated, the reader's gaze is mainly directed towards a small network of socially isolated, prosperous, jet-setting experts. Hence, while The Future of the World does a fine job in capturing - and complicating - a rather distant-feeling moment of high modern hubris, in which a generation of intellectuals projected a communal confidence that the powerful energies of science and technology could be tamed, harnessed and concentrated, one wonders whether it sufficiently conveys what was really at stake when 'the future' was contested.

The final book under review elevates pluritemporality to a comprehensive research agenda. Edited by Dan Edelstein, Stefanos Geroulanos and Natasha Wheatley, Power and Time: Temporalities in Conflict and the Making of History is a penetrating collection of essays which span an extraordinary breadth. Here, one finds minimal focus on monumental 'regimes' of time. What matters instead are the tensions in temporalities that subsist within any set of historical conditions. As the editors argue, the

52 Ibid., p. 22.

53 Ibid. 
temporal landscape of history is neither empty nor static, but always replete with conflict and conflict potential. And, as the essays amply demonstrate, this provides rich pickings for the attentive historian.

The central concept the editors advance is 'chronocenosis', which they introduce as 'a way of theorizing not simply the multiplicity but also the conflict of temporal regimes operating in any given moment'.54 The purpose here is to move away from the 'sedimented' image of synchronous temporalities and instead to unpack the 'contrasts' and 'discords' that exist between them.55 One can immediately see the appeal of such an approach. 'Chronocenosis' not only attunes us to the complex temporal frequencies of power conflicts, but also enables us to locate new conflicts that may otherwise lie hidden from the historian's eye. And these conflicts are manifold. As the editors remind us, temporalities help produce and sustain the very 'non-coevalness established within every social group thanks to gender, class, religion, race, age, technology, and related differentials' .56 That time is also a dynamic site of power contestation has, of course, long been a feature of postcolonial and feminist critiques, among others. But the real value of the framework advanced in Power and Time is that it enables historians to locate similar phenomena in other contexts. As such, there are seemingly few domains of historical research that could not benefit from this approach.

The dazzling diversity of these essays is testament to this. To take just a random handful of examples, one reads Maria Stavrinaki on how George Bataille's understanding of the historicity of prehistory was reflexively anchored in a post-war notion of 'post-history'; Marwa Elshakry on how the nineteenth-century pursuit of a 'universal history' of science led to the invention of a 'Muslim Golden Age'; Dan Edelstein on the temporal thrust particular to revolutionary political legitimacy; Andrea Westermann on geological times and the temporal challenges presented by the Anthropocene; and Claudia Verhoeven on the eschatological temporality of the Manson Family. Often, these are distilled versions or segments of larger projects, giving some indication of the rich wealth of research currently being undertaken on the history of time conflicts.

A particularly effective showcase of the 'chronocenosis' approach is Natasha Wheatley's essay on the frictions produced by the intrusion of 'historical rights' into ideal concepts of modern sovereignty: that is to say, how modern state forms have been 'forced to wrestle with bodies of law and bundles of rights that [stem] from a time before the advent of their own sovereignty'.57 She explores these temporal vexations through two illuminating case studies: indigenous rights in Australia in the latter part of the twentieth century and the ancient feudal and national rights that were articulated in the face of the centralising constitutionalism of the post-1848 Habsburg Empire. A particular advantage of Wheatley's approach is that it helps reveal the dense imbrication of the temporal upon the spatial in questions concerning the evolution of state power. Much as modern notions of 'sovereignty' depended on a perfect mastery of territorial space, so too were they predicated on an ideal dominion of time. The modern polity is therefore philosophically predisposed to struggle when confronted with claims to rights which seem to emanate from outside its sphere of temporal sovereignty.58 And as a result, the irrepressible secretion of the past into the present has proved to be profoundly inconvenient. As with

54 Dan Edelstein, Stefanos Geroulanos, and Natasha Wheatley, 'Chronocenosis: An Introduction to Power and Time' in Dan Edelstein, Stefanos Geroulanos and Natasha Wheatley (eds), Power and Time: Temporalities in Conflict and the Making of History (Chicago: Chicago University Press, 2020), p. 4.

55 Ibid., p. 20.

56 Ibid., p. 23.

57 Natasha Wheatley, 'Legal Pluralism as Temporal Pluralism: Historical Rights, Legal Vitalism, and NonSynchronous Sovereignty' in Edelstein, Geroulanos and Wheatley Power and Time, p. 53.

58 Ibid., p. 54. 
the modern discipline of history, the haunting presence of the past is not something which modern states are readily equipped to deal with.

We shall have to wait and see whether 'chronocenosis' takes on a life of its own, or whether it is swallowed by the rising tide of specialist jargon that 'time studies' appear to be accumulating. Faced with the daunting capaciousness of the concept 'time', it seems, historians compulsively search for qualifiers. But one wonders whether we may again become comfortable simply using the word 'time' as an encompassing category of analysis, much like 'gender' or 'culture'. Either way, one must hope that the basic thrust of the 'chronocenosis' approach survives, for it seems to offer a genuinely productive foundation on which to expand the historical study of time in a very practical - and global - sense. Even those essays that do not engage directly with the concept offer rich possibilities for a more reflective engagement with the dynamic relationship between power and temporality. The book's subject matter is expansive, its temporal registers vast. It is unlikely that any one researcher will find everything in this volume useful. But, at the same time, it is difficult to imagine a historian who could not benefit in some way from consulting it.

The challenges with which these six books present us extend far beyond the narrow scope of this essay: space has prevented me from discussing in any depth the attention given to the new temporal thinking generated by literature on the Anthropocene, for example. Nevertheless, in terms of contemporary European history, the consequence of these works can be summarised as threefold. First, they disclose the potential of one particular field of inquiry - intuitions and articulations of time - in developing some qualitative parameters for defining our contemporary epoch. Secondly, they provide innovative points of departure for grasping how contemporary European experiences of historical time might - or might not - differ from previous ones. Lastly, and most significantly, they point towards the emergence of a conceptual toolkit for a more self-reflective and critical approach to the writing of contemporary history; one which engages explicitly with the particular power dynamics that were built into the very structure of history as a modern and Eurocentric discipline.

Writing in 2011 on the theme of " Contemporary" History and the Historical Discipline', Jan Palmowski and Kristina Spohr remarked that 'contemporary historians have a particular relationship to historical time' .59 The books under review here all, in their own ways, shed some light on how this relationship might be configured. But if there is one overarching message, it is that historians - and not just contemporary historians - need to let go of what Aleida Assmann terms the 'pure past', and the attendant assumption, sacrosanct to the modern time regime, that any event or historical process simply congeals into something called 'the past' 'all on its own — entirely independent of what humans think, do, or will — and as a natural function of linear time'.60 'Presentism' remains a problematic term, but it can no longer be seen simply as a destructive breach in the dam wall that historians have so carefully constructed between present and past. However diverse their approaches and conclusions, the new works on 'presentism' and historical time compel us to reflect - and reflect deeply - on how the 'active' past with which contemporary historians are concerned might burst the boundaries of our modernist chronology.

59 Jan Palmowski and Kristina Spohr Readman, 'Speaking Truth to Power: Contemporary History in the Twenty-first Century', Journal of Contemporary History 46, 3 (2011), p. 502.

60 Assmann, Is Time out of Joint?, p. 130. 